\title{
Occurrence and risk factors for surgical site infection following caesarean delivery: a hospital-based case-control study.
}

\author{
Sedina Kvalvik ${ }^{1}$, Svein Rasmussen², Heidi Thornhill ${ }^{1}$, and Elham Baghestan ${ }^{2}$ \\ ${ }^{1}$ Haukeland Universitetssjukehus \\ ${ }^{2}$ University of Bergen
}

September 16, 2020

\begin{abstract}
Abstract Objective To examine the occurrence and independent risk factors for surgical site infection (SSI) after caesarean section (CS). Design A hospital-based case-control study. Setting University Hospital. Population Women who were readmitted with SSI after CS during the years 2014-2016 $(n=75)$. Controls were selected at a ratio of 2:1 $(n=148)$. Methods Cases (women with SSI following CS) and controls (women without SSI following CS) were compared with respect to maternal and pregnancy characteristics using multivariable logistic regression analysis. Main Outcome Measures Anticipated risk factors for SSI. Results The occurrence of SSI requiring rehospitalisation was $0.38 \%$ and $5.5 \%$ after elective and emergency CS, respectively. Obesity was four times more common in women with SSI than in women without SSI (OR 4.1,95\% CI 1.5-11.3). Signs of infection during labour was almost five times more common (OR 4.7, 95\% CI 1.7-13.0). Attempted vaginal delivery by pushing before CS was more than five times more common (OR 5.6, 95\% CI 1.3-24.3). Pre-existing psychiatric disease was a significant predictor for SSI. Conclusions Emergency CS was a significant characteristic for SSI. Obesity, signs of infection prior to delivery, attempt of vaginal delivery by pushing before CS and pre-existing psychiatric disease, were independent risk factors for SSI. Women with either of these risk factors should be carefully monitored and evaluated for signs of infection in the postpartum period.
\end{abstract}

\section{Hosted file}

Occurrence and risk factors for SSI BJOG.docx available at https://authorea.com/users/359235/ articles/481501-occurrence-and-risk-factors-for-surgical-site-infection-followingcaesarean-delivery-a-hospital-based-case-control-study 